\title{
Agreement between ECG values obtained in the sternal recumbent position and right lateral recumbency in goats
}

\author{
OLGA SZALUŚ-JORDANOW, MICHAŁ CZOPOWICZ*, OKTAWIA SZPINDA**, \\ MARCIN MICKIEWICZ*, AGATA MOROZ*, JAROSŁAW KABA*, \\ MAGDALENA GARNCARZ**, TADEUSZ FRYMUS
}

\begin{abstract}
Division of Infectious Diseases, Department of Small Animal Diseases with Clinic, *Division of Veterinary Epidemiology and Economics,

**Department of Pathology and Veterinary Diagnostics, Institute of Veterinary Medicine, Warsaw University of Life Sciences, Nowoursynowska 159c, 02-776 Warsaw, Poland
\end{abstract}

\section{Szaluś-Jordanow O., Czopowicz M., Szpinda O., Mickiewicz M., Moroz A., Kaba J., Garncarz M., Frymus T. Agreement between ECG values obtained in the sternal recumbent position and right lateral recumbency in goats}

\section{Summary}

The aim of the study was to analyze if body positioning during electrocardiogram recording has an influence on the results in goats. Forty-seven Polish White Improved and Polish Fawn Improved goats from a large dairy herd selected for sanitary culling due to caprine arthritis-encephalitis virus (CAEV) infection, ranging from 2-12 years (median 5.5 years) were included in the study. ECG records were obtained from each goat in the sternal recumbent position and in right lateral recumbency using ASPEL AsCARD Mr. Silver machine with a frequency range of 0.05-150 Hz. The signals from leads I, II, III, aVR, aVL and aVF were recorded for 30 seconds. The mean values of $P, Q R S, T, P Q, Q T, P-R$ duration (in sec) and $P, Q, R, S, T$ waves amplitude (mV) were measured and analyzed. Values obtained in both positions did not differ significantly.

Keywords: electrocardiography, goat, agreement, position

Electrocardiography provides information on the electrophysiological function of the heart, mainly on rhythmicity, conduction, depolarization and repolarization. In dogs (and some other animal species) electrocardiogram (ECG) recordings are obtained in different positions: right or left lateral recumbency, standing freely or in a sling, sitting position, anaesthetized and placed in dorsal recumbency $(2,4,6,13)$. It is well known that many factors may influence ECG recordings. One of these factors is the body position of the patient. Body position changes in humans may cause QRS and ST-T changes and trigger false alarms (9). Such effects have also been recognized in $\operatorname{dogs}(6,13$, $15)$ and even position-specific reference ranges were suggested for this species to avoid misinterpretation (13). The Academy of Veterinary Cardiology recommended that ECGs should be obtained from dogs placed in right lateral recumbency with the forelimbs perpendicular to the long axis of the body and the dog lightly restrained by an assistant. The main advantage of recording an ECG in lying position is that muscle tremor artefacts are reduced (2). On the other hand, lateral recumbency is usually more stressful for the animal.

Publications about the technique of ECG recording in goats and reference values for this species are sparse. Normal ECG values were determined on 16 Jamunapari goats (8), 50 Markhoz goats (3), 20 Black Bengal goats (12), 48 Black Bengal goats (1), 118 Iranian Najdi goats (11) in standing position, 19 Saanen goats in right lateral recumbency (10). In some studies, possible breed differences in ECGs obtained from healthy goats have been suggested $(8,10)$ as well as the need for better understanding of the caprine ECG, especially with regards to its variability (8). To date, the optimal position for obtaining an accurate and reproducible ECG in goats has not been investigated. Therefore, the aim of this study was to compare the results obtained from the same goats in the sternal recumbent position with recordings in right lateral recumbency. 


\section{Material and methods}

Forty-nine female Polish White Improved and Polish Fawn Improved goats from a large dairy herd were enrolled into this study. Their age ranged from 2 to 12 years with a median of 5.5 years and interquartile range (IQR) between 3.7 and 7.1 years. They were all intended for sanitary culling due to infection by caprine arthritis-encephalitis virus (CAEV) as confirmed by ELISA (ID Screen MVV/CAEV Indirect - Screening test, ID.vet Diagnostics, France) detecting anti-CAEV antibodies. The auscultation of all 49 goats were normal. Standard 6-lead ECGs were recorded with leads I, II, III, aVR, aVL and aVF. Using alligator clips the electrodes were attached in the same places for both positions studied: on both chest limbs directly behind the elbow on the skin fold between the limb and chest, and on both abdominal limbs cranially to the pelvic limb on the skin fold between the limb and abdomen. Ethyl alcohol and electrocardiography gel (Aquasonic, Parker Laboratories) were applied to aid transmission of electro activity. From each animal ECGs were recorded in 2 positions: right lateral recumbency and sternal recumbency. Keeping the animals in the lateral position required gentle restraint by 2 persons. In the sternal position only one person was needed. ECGs were obtained using an ASPEL AsCARD Mr. Silver machine with a frequency range of 0.05-150 Hz. The signals from all 6 leads were recorded for 30 seconds and the ECGs strips were printed at $50 \mathrm{~mm} / \mathrm{s}$ and $10 \mathrm{~mm} / \mathrm{mV}$ parameters. For each goat in each position the mean of 3 consecutive values of P, QRS, T, PQ, QT,P-R duration (in sec) and P, Q, R, S, T waves amplitude $(\mathrm{mV})$ were calculated by two independent evaluators. Records with severe tremor artefacts disturbing interpretation of the $\mathrm{P}$ and $\mathrm{T}$ waves were excluded from the evaluation.

The mean ECG values obtained in the 2 positions were expressed as the median, interquartile range (IQR) and range and were compared using the paired-sample t-test or Wilcoxon's signed-rank test unless their differences were normally distributed according to the Shapiro-Wilk W test. Correlation between heart rate (HR) and ECG measurements was calculated separately for each position using Spearman's rank-order correlation coefficient ( $\left.r_{s}\right)$. A significance level $(\alpha)$ was set at 0.05 . The statistical analysis was performed using Statistica 12 (StatSoft, Inc.).

\section{Results and discussion}

Among the 49 obtained ECGs, 2 were illegible in both positions because of severe tremors. The values of the remaining 47 goats are presented in Table 1 . No significant differences between the values obtained in the two positions were found (Tab. 1). In most goats left hearth axis deviation was observed regardless of the
Tab. 1. ECG measurements (median, IQR, range) in 47 dairy goats in sternal recumbency versus right lateral recumbency

\begin{tabular}{|c|c|c|c|c|}
\hline \multirow{2}{*}{$\begin{array}{c}\text { ECG } \\
\text { parameter }\end{array}$} & \multicolumn{2}{|c|}{ Position } & \multirow{2}{*}{$\begin{array}{c}\text { Normality of } \\
\text { difference distribution }\end{array}$} & \multirow{2}{*}{$p$} \\
\hline & Sternal & Right lateral & & \\
\hline HR [bpm] & $\begin{array}{c}100,90-130 \\
(80-160)\end{array}$ & $\begin{array}{c}100,90-120 \\
(70-180)\end{array}$ & 0.037 & 0.537 \\
\hline $\mathbf{P}_{\text {dur }}[\mathbf{s}]$ & $\begin{array}{c}0.04,0.04-0.05 \\
(0.03-0.07)\end{array}$ & $\begin{array}{c}0.05,0.04-0.05 \\
(0.03-0.06)\end{array}$ & 0.361 & $0.168^{\circ}$ \\
\hline $\mathbf{P}_{\mathrm{amp}}[\mathrm{mV}]$ & $\begin{array}{c}0.11,0.07-0.14 \\
(0.02-0.20)\end{array}$ & $\begin{array}{c}0.10,0.09-0.13 \\
(0.05-0.18)\end{array}$ & 0.943 & $0.129^{2}$ \\
\hline $\mathrm{PQ}_{\mathrm{dur}}[\mathrm{s}]$ & $\begin{array}{c}0.09,0.08-0.10 \\
(0.05-0.63)\end{array}$ & $\begin{array}{c}0.09,0.08-0.10 \\
(0.06-0.17)\end{array}$ & $<0.001$ & 0.073 \\
\hline $\mathrm{QRS}_{\mathrm{dur}}[\mathrm{s}]$ & $\begin{array}{c}0.06,0.05-0.07 \\
(0.04-0.07)\end{array}$ & $\begin{array}{c}0.06,0.05-0.06 \\
(0.03-0.08)\end{array}$ & 0.315 & $0.372^{2}$ \\
\hline $\mathbf{a}_{\mathrm{amp}}[\mathrm{mV}]^{\mathrm{c}}$ & $\begin{array}{c}0.09,0.05-0.16 \\
(0.03-0.30)\end{array}$ & $\begin{array}{c}0.13,0.06-0.17 \\
(0.05-0.23)\end{array}$ & 0.360 & 0.901 \\
\hline $\mathbf{R}_{\mathrm{amp}}[\mathrm{mV}]$ & $\begin{array}{c}0.05,0.04-0.10 \\
(0.02-0.45)\end{array}$ & $\begin{array}{c}0.05,0.03-0.14 \\
(0.01-0.6)\end{array}$ & $<0.001$ & 0.451 \\
\hline $\mathrm{S}_{\mathrm{amp}}[\mathrm{mV}]$ & $\begin{array}{c}0.33,0.14-0.50 \\
(0.01-2.00)\end{array}$ & $\begin{array}{c}0.33,0.17-0.38 \\
(0.05-1.08)\end{array}$ & $<0.001$ & 0.978 \\
\hline $\mathbf{Q T}_{\mathrm{dur}}[\mathrm{s}]$ & $\begin{array}{c}0.29,0.25-0.31 \\
(0.12-0.35)\end{array}$ & $\begin{array}{c}0.29,0.25-0.31 \\
(0.08-0.35)\end{array}$ & 0.001 & 0.806 \\
\hline $\mathrm{ST}_{\mathrm{amp}}[\mathrm{mV}]$ & $\begin{array}{c}0,0-0.03 \\
(-0.5-0.13)\end{array}$ & $\begin{array}{c}0,0-0.04 \\
(-0.08-0.58)\end{array}$ & $<0.001$ & 0.404 \\
\hline $\mathrm{T}_{\text {dur }}[\mathrm{s}]$ & $\begin{array}{c}0.07,0.06-0.09 \\
(0.04-0.12)\end{array}$ & $\begin{array}{c}0.07,0.06-0.09 \\
(0.05-0.21)\end{array}$ & $<0.001$ & $0.717^{\prime}$ \\
\hline $\mathrm{T}_{\mathrm{amp}}[\mathrm{mV}]$ & $\begin{array}{c}0.39 .0 .23-0.6 \\
(0.08-1.60)\end{array}$ & $\begin{array}{c}0.47,0.27-0.57 \\
(0.05-1.65)\end{array}$ & 0.330 & $0.468^{\circ}$ \\
\hline Axis $\left[{ }^{\circ}\right]$ & $\begin{array}{c}-73.7,-101-50.7 \\
(-165.3-172.3)\end{array}$ & $\begin{array}{c}-50.7,-121.7-71.7 \\
(-173.3-178.7)\end{array}$ & $<0.001$ & 0.966 \\
\hline
\end{tabular}

Explanations: $\mathrm{a}$ - paired-sample t-test; $\mathrm{b}$ - Wilcoxon's signed-rank test; $\mathrm{c}-\mathrm{me}$ asured in 7 goats only

Tab. 2. Hearth axis and its deviation in 47 dairy goats in sternal recumbency versus right lateral recumbency

\begin{tabular}{|l|r|r|}
\hline \multicolumn{1}{|c|}{ Heart axis } & \multicolumn{2}{|c|}{ Position } \\
& Sternal & Right lateral \\
\hline Normal & $5(11 \%)$ & $9(19 \%)$ \\
Left axis deviation & $33(70 \%)$ & $28(60 \%)$ \\
Right axis deviation & $9(19 \%)$ & $10(21 \%)$ \\
\hline
\end{tabular}

position during ECG recording (Tab. 2). The median HR was 100 beats per minute (bpm) in both positions (Tab. 1). Correlation between HR and ECG findings in 47 goats in the sternal recumbent position versus right lateral recumbency is presented in Table 3.

Our study showed no HR differences in goats examined in the sternal recumbent position or in lateral recumbency (Tab. 1). A similar comparison in dogs examined in standing or in lateral recumbency also showed no differences in the HR. The median value in our goats was $100 \mathrm{bpm}$ (range 80-160), which was similar to the mean values reported by Szabuniewicz for cross-bred goats (96 bpm) (16), and for Black Bengal goats (101 bpm) (1), lower than mean rates obtained by Pogliani et al. for Saanen goats (129 bpm) (10), Mohan et al. for Jamunapari goats (127 bpm) (8) and Fakour et al. for Markhoz goats (110 bpm) (3), but 
Tab. 3. Correlation between heart rate (HR) and ECG findings in $\mathbf{4 7}$ dairy goats in sternal recumbency versus right lateral recumbency

\begin{tabular}{|c|c|c|c|c|}
\hline $\begin{array}{c}\text { ECG } \\
\text { parameter }\end{array}$ & $\begin{array}{c}\text { Sternal } \\
r_{s}\end{array}$ & $p$ & $\begin{array}{c}\text { Right lateral } \\
r_{s}\end{array}$ & $p$ \\
\hline $\mathbf{P}_{\text {dur }}[\mathbf{s}]$ & -0.15 & 0.321 & -0.02 & 0.919 \\
\hline $\mathbf{P}_{\mathrm{amp}}[\mathrm{mV}]$ & -0.16 & 0.294 & -0.04 & 0.788 \\
\hline$P Q_{d u r}[s]$ & -0.02 & 0.919 & -0.19 & 0.194 \\
\hline $\mathrm{QRS}_{\text {dur }}[\mathrm{s}]$ & -0.19 & 0.207 & 0.02 & 0.909 \\
\hline$Q_{a m p}[m V] c$ & -0.73 & 0.063 & -0.20 & 0.598 \\
\hline $\mathbf{R}_{\mathrm{amp}}[\mathrm{mV}]$ & -0.19 & 0.190 & -0.05 & 0.722 \\
\hline $\mathrm{S}_{\mathrm{amp}}[\mathrm{mV}]$ & -0.16 & 0.270 & 0.08 & 0.585 \\
\hline $\mathrm{QT}_{\mathrm{dur}}[\mathrm{s}]$ & -0.75 & $<0.001^{*}$ & -0.64 & $<0.001^{*}$ \\
\hline$S \mathbf{S T}_{\text {amp }}[\mathrm{mV}]$ & -0.11 & 0.466 & -0.14 & 0.364 \\
\hline$T_{\text {dur }}[\mathbf{s}]$ & -0.33 & $0.024^{*}$ & -0.05 & 0.718 \\
\hline $\mathrm{T}_{\mathrm{amp}}[\mathrm{mV}]$ & -0.24 & 0.103 & -0.12 & 0.429 \\
\hline Axis $\left[{ }^{\circ}\right]$ & 0.20 & 0.182 & -0.17 & 0.241 \\
\hline
\end{tabular}

higher than those observed by Kant et al. for cross-bred goats $(90 \mathrm{bpm})(7)$. These differences can reflect breed specificity; however, goats of different age were used in the studies mentioned above, and age is an important factor determining the HR. As shown in Table 3 the only ECG measurements linked to HR in our goats were QT duration and T duration: QT duration was negatively correlated with HR (i.e. decreased as HR was rising), and this was observed in both positions. A similar effect was found in beagles (6). Additionally, $\mathrm{T}$ duration in our goats was also negatively correlated with HR, but only in animals examined in the sternal position.

It has been suggested that the electrical axis may not have a good clinical value to monitor pathological heart alterations in goats, as a wide range of this value is usually observed in normal animals $(1,8,10)$. Our results seem to support this suggestion, as only $11 \%$ to $19 \%$ animals had normal electrical axis, depending on the body position at recording (Tab. 2).

Some studies in dogs demonstrated that the position of the body, and especially of the forelimbs, may influence the ECG records $(13,15)$.

In right lateral recumbency the cardiac silhouette moves closer to the right lung and to the electrodes potentially augmenting voltages on the right side of the patient (14). Some studies have shown, that this position results in dogs also in a rightward shift in the mean electrical axis, as compared with records obtained in standing (13-15). However, this seems not to be a general rule, as the effects of lateral versus sternal recumbent positions for ECG recording in cats of various breeds and age could hardly be demonstrated (5). Moreover, we did not find significant differences in ECG values obtained in goats in sternal recumbency and in right lateral recumbency (Tab. 1). This would mean that position-specific reference ranges of ECG values are not necessary in goats.

\section{References}

1. Ahmed J., Sanyal S.: Electrocardiographic Studies in Garol Sheep and Black Bengal Goats. Res. J. Cardiol. 2008, 1, 1-8.

2. Coleman M., Robson M.: Evaluation of Six-Lead Electrocardiograms Obtained from Dogs in a Sitting Position or Sternal Recumbency. Am. J. Vet. Res. 2005, 66, 233-237.

3.Fakour S., Dezfuli M., Nadalian M., Rezakhani A., Lotfollah Zadeh S.: Electrocardiographic Parameters of Markhoz Goat Using Base Apex Lead and Six Standard Limb Leads. Iran. J. Vet. Res. 2013, 3, 241-244.

4. Garncarz M., Parzeniecka-Jaworska M., Jank M., Łój M., Szaluś-Jordanow O., Kurek A.: Lead II Electrocardiography in Standing and Right Lateral Recumbency in Dogs with Normal Echocardiographic Heart Chamber Values. Bull. Vet. Inst. Pulawy 2013, 57, 263-267.

5. Gompf R., Tilley L.: Comparison of Lateral and Sternal Recumbent Positions for Electrocardiography of the Cat. Am. J. Vet. Res. 1979, 10, 1483-1486.

6. Hanton G., Rabemampianina Y.: The Electrocardiogram of the Beagle Dog: Reference Values and Effect of Sex, Genetic Strain, Body Position and Heart Rate. Lab. Anim. 2006, 40, 123-136.

7. Kant V., Srivastava A., Verma P., Raina R., Pankaj N.: Alterations in Electrocardiographic Parameters after Subacute Exposure of Fluoride and Ameliorative Action of AluminiumSulphate in Goats. Biol. Trace Elem. Res. 2010, 134, 188-194.

8. Mohan N., Niyogi D., Singh H.: Analysis of Normal Electrocardiograms of Jamunapari Goats. J. Vet. Sci. 2005 6, 295-298.

9. Nelwan S., Meij S., van Dam T., Kors J.: Correction of ECG Variations Caused by Body Position Changes and Electrode Placement during ST-T Monitoring. J. Electrocardiol. 2001, 34 Suppl, 213-216.

10. Pogliani F., Birgel Junior E., Monteiro B., Grisi Filho J., Raimondo R.: The normal electrocardiogram in the clinically healthy Saanen goats. Pesq. Vet. Bras. 2013, 33, 1478-1482.

11. Pourjafar M., Badiei K., Sanati A., Shahbazi A., Badkobeh M., Bagheri M.: Age-related cardiac arrhythmias in clinically healthy Iranian Najdi goats. Bulg. J. Vet. Med. 2012, 15, 37-43.

12. Pradhan R., Mahapatra A., Mohapatra S., Jyotiranjan T., Kundu A.: Electrocardiographic Reference Values and Configuration of Electrocardiogram Waves Recorded in Black Bengal Goats of Different Age Groups. Vet. World. 2017, 10, 1020-1025.

13. Rishniw M., Porciello F., Erb H., Fruganti G.: Effect of Body Position on the 6-Lead ECG of Dogs. J. Vet. Intern. Med. 2002, 16, 69-73.

14. Spencer C., Ackerman N., Burt J.: The canine lateral thoracic radiograph. Vet. Radiol. 1981, 22, 262-266.

15. Stern J., Hinchcliff W., Constable P.: Effect of Body Position on Electrocardiographic Recordings in Dogs. Aust. Vet. J. 2013, 91, 281-286.

16. Szabuniewicz M., Clark D.: Analysis of the Electrocardiograms of 100 Normal Goats. Am. J. Vet. Res. 1967, 28, 511-516.

Corresponding author: Olga Szaluś-Jordanow, DVM, PhD, Nowoursynowska St. 159c, 02-776 Warsaw, Poland; e-mail: olga_szalus_jordanow@ sggw.edu.pl 